
Abdulkadir I
Hassan L
Abdullahi F
Akeredolu FD
Purdue S
Okpe M
Sobowale AM
Adewumi OA
Abdullahi U
Onadiran MA
Sholadoye TT
Baba S
Ogala WN

DOI:http://dx.doi.org/10.4314/njp.v42i3.14

Accepted: 18th May 2015

Abdulkadir I ( $\boldsymbol{\nabla})$

Hassan L, Abdullahi F, Akeredolu FD

Purdue S, Okpe M, Sobowale AM,

Adewumi OA, Abdullahi U

Onadiran MA, Ogala WN

Department of Paediatrics

Ahmadu Bello University Teaching

Hospital Shika - Zaria, Kaduna State

Nigeria.

Email: isaburamla@yahoo.com

Sholadoye TT, Baba S

Department of Surgery,

Ahmadu Bello University Teaching

Hospital Shika - Zaria, Kaduna State

Nigeria.

\title{
Accidental sulphuric acid poisoning in a newborn
}

\section{Introduction and literature review}

Corrosives or caustics are a group of chemicals that have the capacity to cause tissue injury on contact by a chemical reaction ${ }^{1}$. Ingestion of caustic substances can cause gastrointestinal and upper airway injuries and can result in lifelong complications like oesophageal stricture, laryngeal stenosis and later, increased risk of oesophageal cancer ${ }^{2}$.

Acids and alkalis are the two primary types of agents most often responsible for caustic exposures but with differing injury mechanisms ${ }^{3,4}$. While alkaline agents cause widespread liquefaction necrosis injury along contact areas, ${ }^{3}$ acid substances cause coagulative necrosis with resultant eschar formation which tends to limit tissue penetration and further injury ${ }^{4}$.

Alkali is partly neutralized by gastric secretion thus minimizing gastric mucosal injury conversely acids usually provoke the most severe gastric lesions, especially in the antropyloric region ${ }^{3}$. Oesophageal wall injury following acid ingestion peaks between 1and 3 weeks while the healing process spans $4-6$ weeks $^{5-7}$.

The magnitude of the injury depends upon several factors such as the nature of the caustic agent, volume ingested, concentration, duration of mucosal exposure, age of the patient and the intent (suicidal or accidental) with which the corrosive was consumed ${ }^{7,8}$.

Corrosive ingestion in children may cause clinical manifestations varying from no injury to fatal outcome. Early signs and symptoms after caustic ingestion may not be consistent with the extent of damage and endoscopy performed on day 1-2 (ideally between 12-24 hours of ingestion) is used to assess injury ${ }^{6,9,10}$.

Recommended management protocols include resting the esophagus or the entire gastrointestinal tract using parenteral nutrition, the use of broad-spectrum antibiotics, systemic steroids, antacids, proton pump inhibitors and $\mathrm{H}_{2}$ receptor - blockers ${ }^{11,12}$. 
Unlike in adults where ingestion is deliberate, most ingestions by children are accidental. ${ }^{13}$ Globally, children represent $80 \%$ of the corrosive ingestion injury population $^{8}$ with children less than 5 years most affected. ${ }^{14}$ Corrosive ingestion accounted for $0.5 \%$ of paediatric admissions in Nigeria. ${ }^{15-19}$ The probability of ingestion of a caustic agent is low in the newborn period and newborn caustic burns have been reported infrequently in Nigeria and globally and remains a rarity. ${ }^{16,17}$ We report a case of a newborn with accidental sulphuric acid ingestion within the first hour of life a rare and sparsely reported occurrence.

\section{Case report}

Baby JZ, a 6 hour old term baby girl, was rushed to the Special Care Baby Unit of Ahmadu Bello University Teaching Hospital Zaria following accidental ingestion of acid 5 hours prior to presentation. The acid, mistaken for holy water, ruwan zam zam was administered by the paternal grandmother who had taken the baby home for a bath while the mother was still in the hospital. Her 8 year old step sister was asked to get the holy water but accidentally brought the acid stored in an unlabeled, small, white, plastic keg similar to the one containing the holy water (fig 1) kept in an unlocked drawer in the mother's bed room. The acid was given directly from the container to the baby. She began to choke after taking about two sips, and started coughing and retching repeatedly. She vomited blood twice, about 20-25 mls per bout and subsequently developed difficulty with breathing which persisted till presentation. There was no intervention at home. Baby was rushed to the Primary Healthcare Centre (PHC) where she was delivered and was then referred to our facility immediately but arrived about five hours later due to transportation logistics. There was no fever and no bleeding from any other bodily orifices.

Pregnancy was supervised in a private hospital and mother had pregnancy induced hypertension in the $3^{\text {rd }}$ trimester which was controlled with antihypertensives $(\alpha$ - methyl dopa and amiloride $\mathrm{HCl}$ - hydrochlorothiazide combination). Delivery was at a PHC via spontaneous vertex delivery and baby cried immediately after birth.

Baby was the $2^{\text {nd }}$ child of the mother who is a 22 year old house wife. Father is a 35 year old commercial motor cycle rider who also sells perfumes. They both have primary education. Marriage setting is polygamous with two wives and six children. They reside in a 4-room apartment. The battery liquid was being used by the father to refill his motorcycle battery acid.

At presentation, baby was ill-looking, wheezing, pale, tachypnoeic and dyspnoeic $\mathrm{SPO}_{2}$ was $86 \%$. There was no petechiae rash. She was conscious but irritable, anterior fontanelle was normotensive, had normal tone but the primitive reflexes were depressed. Mouth examination showed dried blood on the lips, there was no hyperaemia, swellings or ulcerations on lips, buccal mucosa or tongue. Respiratory rate was $80 \mathrm{cpm}$ (tachypnoea) with wide spread crepitation and rhonchi. Her heart rate was $160 \mathrm{bpm}$, regular, and heart sounds were normal. There were no abnormal abdominal findings.

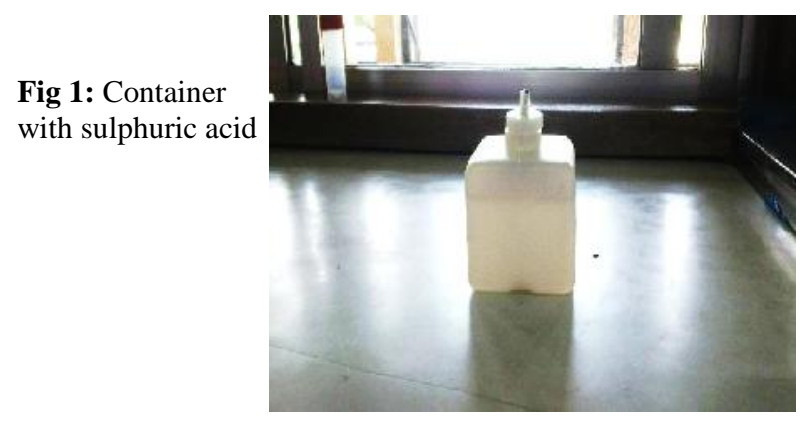

A diagnosis of accidental corrosive ingestion with complications of upper gastrointestinal (GI) bleeding and chemical pneumonitis was made. She was commenced on supportive therapy including: Nil per oral, oxygen therapy at $1.5 \mathrm{~L} / \mathrm{min}$ via nasal catheter, intravenous fluids, parenteral antibiotics (crystalline penicillin, metronidazole and gentamicin), steroids (hydrocortisone for 48 hours), intravenous ranitidine and a nasogastric tube (NGT) was passed. Chest x-ray (Fig 2) done at admission showed diffuse patchy opacity while her serum urea and electrolyte were normal. Within 24 hours of admission, she developed massive upper GI bleeding with abdominal distension, severe pallor, cold extremities, thready peripheral pulses and unrecordable BP, and NGT was draining fresh blood. She was resuscitated with normal saline and received multiple blood transfusions in aliquots on account of the bleeding which lasted for about 72 hours. On the $3^{\text {rd }}$ day of life, she developed fever, worsened abdominal distension, tenderness and guarding, with hypoactive bowels.

Erect abdominal x-ray (Fig 3) showed air under the diaphragm. A diagnosis of bowel perforation with peritonitis was made. Baby was managed conservatively for bowel perforation with improvement in clinical condition. She was on partial parenteral nutrition of $7.5 \%$ dextrose in 0.18 saline and amino acid infusion at $0.25 \mathrm{mg} / \mathrm{kg} /$ day with daily potassium maintenance in 24 hour fluid. Baby did not have NGT feeding as she developed repeated bilious vomiting from the $2^{\text {nd }}$ week on admission. She was still opening her bowel and passing bile stained stools. She could not have early endoscopy however, gastrograffin contrast study showed normal oesophagus. She was planned for exploratory laparatomy and feeding jejunostomy, but her clinical condition deteriorated as she developed widespread petechiae rash, severe pallor, difficulty with breathing, severe electrolyte derangement and died in the course of resuscitation at the age of 24 days. The parents declined postmortem.

Fig 2: Chest $X$ - ray.

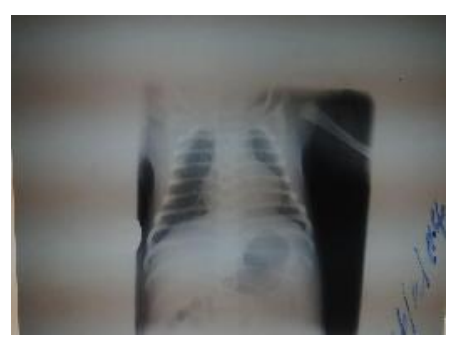


Fig 3: Erect Abdominal Xray.

Arrow showing air under the $(\mathrm{R})$ hemi diaghragm

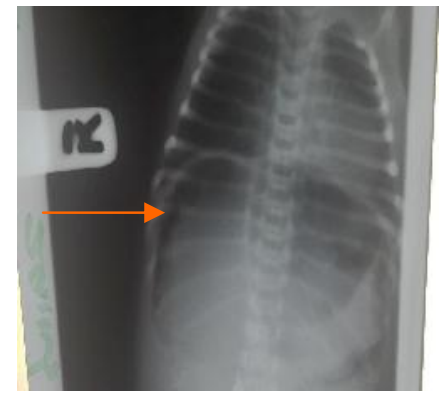

\section{Discussion}

Exposure to corrosive agents continues to be a major source of injury for children and adults however it remains a rare occurrence in newborns. Our patient ingested sulphuric acid which was accidentally administered to her like in most cases of corrosives ingestion in children $^{1}$. Sulphuric acid is one of the commonly ingested substances associated with caustic injury ${ }^{1}$.The types of corrosive agents commonly implicated vary from country to country. In a review of data on corrosive ingestion in children from Sierra Leone ${ }^{14}$, the most reported corrosive agent was caustic soda, followed by kerosene, sodium hypochlorite and other alkaline household chemicals. In India, the majority of ingestions are due to acids and predominantly implicated are toilet cleaning fluid (hydrochloric acid) ${ }^{7}$. In a ten year review in Turkey, corrosive injuries of oesophagus involving 8 newborns were due to benzalkonium chloride and trichloroacetic acid ingestion ${ }^{16}$. Reports from Port Harcourt $^{18}$ and Lagos ${ }^{19}$ in Nigeria have identified caustic soda, bleach, battery acid and shaving powder as ingested corrosives. While none of these reports involved newborns, Kushimo et $\mathrm{al}^{17}$ in Lagos however, reported a case of acid ingestion in a 2 day old neonate.

The ingested sulphuric acid in the index case was kept in an unlocked drawer in the house for use by the father. Documented risk factors ${ }^{14}$ for corrosive ingestion in children include: the availability of chemicals in and around the home, combined with the natural curiosity of children, crowded living conditions and parent's lack of knowledge of the hazards of corrosive substances kept in the house. These are factors that are however not directly related to the newborn since it does not have the ability to reach out to these agents. Perhaps the most important risk factors in this newborn were the introduction of prelacteal feed or drink and the use of familiar containers to store chemicals. This led to the care giver wanting to give holy water but inadvertently offering sulphuric acid which was easily accessible.

The PH of the ingested acid was 0.8 with resultant chok- ing, retching and vomiting which could have led to aspiration and the development of difficulty with breathing with wide spread crepitation. Caustic agents with $\mathrm{pH}$ lower than 2 or greater than 12 are highly corrosive and can cause severe chemical burns in the upper gastrointestinal tract ${ }^{20}$.

Other complications recorded include massive GI haemorrhage and perforation. Strode et $\mathrm{al}^{20}$ documented that immediate perforation of the stomach occurs if the ingested acid is concentrated. The pooling of the caustic acids in the prepyloric area induces pylorospasm which is also thought to predispose patients to gastric perforation and stricture ${ }^{20}$.

Turan et $a l^{16}$ did document sepsis and pneumonia in some of their neonates who ingested caustic solution. In Lagos Kushimo ${ }^{17}$ reported severe respiratory problems in a neonate as complication necessitating intubation.

Morbidity and mortality in cases of ingestion of corrosives in newborn is very high ${ }^{16}$. While Turan ${ }^{16}$ reported sepsis as the possible cause of death in their report $\mathrm{Ku}$ shima ${ }^{17}$ reported necrotizing oesophago -gastritis and lung collapse as the cause of death in their report on a 2day old neonate. Though a postmortem was not performed, the index case possibly died from a combination of complications including bowel perforation, metabolic and electrolyte derangements, consumptive coagulopathy and intracranial bleeding.

\section{Conclusion}

Accidental corrosive ingestion is rare in the newborn but when it occurs, it is associated with high morbidity and mortality.

\section{Recommendations}

Baby JZ accidentally ingested acid mistaken for holy water. This could be prevented by encouraging exclusive breastfeeding (EBF) and vigorously enlightening parents on benefits of EBF which should negate the need of pre lacteal feeds, advocacy and enforcement of regulations of manufacturing, sales and storage of corrosives and as well getting facilities to implement fully the essential newborn care practices part of which encourages skin to skin contact with mother from birth and encourages delaying bathing of the baby until the $2^{\text {nd }}$ day of life.

\section{Conflict of interest: None}

Funding: None 
References

1. Naik RR, Vadivelan M. Corrosive Poisoning. Indian J Clinic Practice 2012; 23:131-34.

2. Lionte C, Sorodoc L, Petris OR, Sorodoc V. Unusual presentation and complication of caustic ingestion. Case Report. J Gastrointestin Liver Dis 2007; 16:109-12

3. Mamede RCM, Filho FVM. Ingestion of caustic substances and its complications. Sao Paulo Med J 2001; 119:10-5.

4. Riffat F, Cheng A. Pediatric caustic ingestion: 50 consecutive cases and a review of the literature. Diseases Esophagus 2009; 22: 89-94.

5. Dilawari JB, Singh S, Rao PN, Anand BS. Corrosive acid ingestion in man a clinical and endoscopic study. Gut 1984; 25:18387.

6. Zargar SA, Kochar R, Nagi B. Ingestion of strong corrosive alkalis: spectrum of injury to upper gastrointestinal tract and natural history. Am J Gastroenterol 1992; 87: 337- 41 .

7. Lahoti D, Broor SL. Corrosive injury to the upper gastrointestinal tract. Indian J Gastroenterol 1993; 12: $135-41$.

8. Gumaste VV, Dave PB. Ingestion of corrosive substances by adults. Am J Gastroenterol 1992; 87:1- 5.
9. Gaudreault P, Parent M, McGuigan MA, Chicoine L, Lovejoy FH Jr. Predictability of Esophageal Injury from Signs and Symptoms: A Study of Caustic Ingestion in 378 Children. Pediatrics 1983; 71 : 767-70.

10. Zargar SA, Kochhar R, Mehta S, Mehta SK. The role of fiberoptic endoscopy in the management of corrosive ingestion and modified endoscopic classification of burns. Gastrointest Endosc 1991;37: 1659.

11. Gun F, Abbasoglu L, Celik A, Salman FT. Early and Late Term Management in Caustic Ingestion in Children : A 16-year Experience. Acta chir belg 2007; 107: 49 $-52$.

12. Rothstein FC. Caustic injuries to the esophagus in children. Pediatr Toxicol Pediatr Clin North Am 1986;33: 665-74.

13. Contini S, Scarpignato C. Caustic injury of the upper gastrointestinal tract: A comprehensive review. World J Gastroenterol 2013; 19 . 3918-30.

14. Contini S, Swarray-Deen A, Scarpignato C. Oesophageal corrosive injuries in children: A forgotten social and health challenge in developing countries. Bull $\mathrm{WHO}$ 2009; 87:950-4.
15. Ogunleye AO, Nwaorgu GB, Grandawa H. Corrosive oesophagitis in Nigeria: clinical spectrums and implications. Trop Doct 2002; 32: 78-80.

16. Turan C, Ozkan U, Ozokutan BH, Ozdemir M, Okur H, kucukaydin M. Corrosive injuries of the esophagus in newborns. Pediatr Surg Int 2000; 16: 483-4.

17. Kushimo T, Ekanem MM. Acid ingestion in a 2-day old baby. West Afri J Med 1997; 16: 121- 23.

18. Onotai LO, Nwogbo AC. Pattern of corrosive ingestion injuries in Port Harcourt: A ten year review. Niger Hlth J 2010; 10: 22-5.

19. Thomas MO, Ogunleye EO, Somefun O. Chemical injuries of the oesophagus: Aetiopathological issues in Nigeria. J Cardiothorac Surg 2009; 4: 56.

20. Strode EC, Dean ML. Acid burns of the stomach; report of 2 cases. Ann Surg 1950; 131: 801-11. 